\title{
Fostering collaboration for knowledge and action in disaster management in South Africa Nadia Sitas ${ }^{1}$, Belinda Reyers ${ }^{1,2}$, Georgina Cundill ${ }^{3}$, Heidi E Prozesky ${ }^{4,5}$, Jeanne L Nel ${ }^{1,6}$ and Karen J Esler ${ }^{7,8}$
}

\begin{abstract}
Engaging diverse stakeholders in collaborative processes to integrate environmental information into decision making is important, but challenging. It requires working at and across the boundaries between knowledge types - a complex milieu of different value systems, norms, and mental models - and multiple stakeholder-engagement processes which facilitate knowledge exchange and co-production. Using a qualitative, inductive approach, we analysed perceptions and outputs of a transdisciplinary project which aimed to generate new knowledge, awareness and action for ecosystem-based disaster management in South Africa. Several obstacles that could potentially undermine the project's objectives were identified, including: preconceived assumptions; entrenched disciplinary thinking; and confusing terminology. Enabling factors included efforts to ensure project cocreation and the use of knowledge brokers in promoting systems thinking that is grounded in practice.
\end{abstract}

\footnotetext{
Addresses

${ }^{1}$ Natural Resources and The Environment, Council for Scientific and Industrial Research, PO Box 320, Stellenbosch, South Africa

${ }^{2}$ Stockholm Resilience Centre, Stockholm University, Kräftriket, 104 05 Stockholm, Sweden

${ }^{3}$ Department of Environmental Science, Rhodes University, PO Box 94, Grahamstown 6140, South Africa

${ }^{4}$ Centre for Research on Evaluation, Science and Technology,

Stellenbosch University, Private Bag X1, Matieland 7602, South Africa

${ }^{5}$ DST-NRF Centre of Excellence in Scientometrics and STI Policy,

Stellenbosch University, Private Bag X1, Matieland 7602, South Africa

${ }^{6}$ Sustainability Research Unit, Nelson Mandela Metropolitan University, Private Bag X6531, George 6530, South Africa

${ }^{7}$ Department of Conservation Ecology and Entomology, Stellenbosch University, Private Bag X1, Matieland 7602, South Africa

${ }^{8}$ Centre for Invasion Biology, Stellenbosch University, Private Bag X1, Matieland 7602, South Africa
}

Corresponding author: Sitas, Nadia (nsitas@csir.co.za)

Current Opinion in Environmental Sustainability 2016, 19:94-102

This review comes from a themed issue on Sustainability science

Edited by Harold Mooney

For a complete overview see the Issue and the Editorial

Received 4 August 2015; Revised 11 December 2015; Accepted 18 December 2015

Available online 30th January 2016

http://dx.doi.org/10.1016/j.cosust.2015.12.007

1877-3435/Published by Elsevier B.V.

\section{Introduction}

Over the last decade the role of healthy ecosystems in providing protection against natural hazards and mitigating the impacts of climate change has been highlighted $\left[1^{\bullet}, 2,3\right]$. Ecosystem-based disaster risk reduction is increasingly receiving attention as a means to boost the ecological buffering capabilities of ecosystems [4]. This approach focuses on conserving or restoring regulating ecosystem services provided by healthy ecosystems [5], such as the role of wetlands in slowing flood waters [6]. Despite its potential, ecosystem-based disaster management remains limited in practice. This is partly due to the complexities involved in exchanging and integrating knowledge from the multiple disciplines, stakeholders, sectors and scales involved in ecosystem management and disaster risk reduction $\left[7^{\bullet}, 8^{\bullet \bullet}, 9^{\bullet \bullet}, 10^{\bullet \bullet}\right]$. Careful design of collaborative processes that generate and facilitate knowledge sharing and use is therefore a potential avenue for addressing the slow uptake of ecosystem-based approaches $\left[8^{\bullet \bullet}\right]$.

Current examples of knowledge exchange for improved ecosystem management $\left[11,12^{\bullet \bullet}\right]$, as well as efforts to integrate ecosystem-based disaster management into multi-sectoral policies in South Africa $\left[9^{\bullet \bullet}, 13^{\bullet \bullet}\right]$, offer potential to integrate ecosystem knowledge into decisions and actions. The latter example, in the Eden District of the Southern Cape region of South Africa, was initiated in response to a recent increase in disasters, related to floods, droughts, storm waves and wildfires. The transdisciplinary project was initiated in 2008 between a national science council, a university, a national insurer, a non-governmental organisation, and local and provincial governments $\left[13^{\bullet \bullet}\right]$. This project (hereafter referred to as 'The Eden project') was established as a short-term project to better understand the impacts and causes of disasters in Eden, identify possible management strategies, and build a longer term collaboration for disaster-risk reduction in the area.

A recent review of the project highlighted numerous successes in moving from research to impact, including new investments in ecosystem restoration, institutional changes in the private and public sectors, and the development of new partnerships between scientists, practitioners and decision makers $\left[9^{\circ \bullet}\right]$. Based on these successes, we aim to analyse the project and identify the factors that facilitated or hindered the project's achievement of it aims, with a particular focus on knowledge co-production among diverse stakeholders. 


\section{Methods}

A qualitative, inductive approach informed by grounded theory methodology [14] was used, which involved an iterative process between data collection and analysis.

\section{Data collection}

Using purposive and snowball sampling [15], 19 participants were selected as informants as they were key roleplayers in the knowledge co-production process. These participants, in almost all instances, represented the key participants from the respective institutions involved in the study. However, due to time restraints, we did not interview all implementing agents involved in the project (see Table 2) but instead selected leaders, or those participants from the main institutions most involved in the project. Semi-structured interviews (of approximately 45 minutes each) were conducted with these participants between May 2013 and April 2014 by the lead author. Interviews were primarily face-to-face but some were telephonic, and participants consented to the interviews which were digitally voice-recorded and then transcribed by the lead author (Table 1). To complement the interviews, key project outputs (e.g. project reports of the different institutions involved in the project; project presentations of research findings from workshops/meetings) and related information (e.g. institutional websites; meeting minutes; plans) were collected for analysis.

\section{Data analysis}

The analytic process comprised a series of iterative steps exploring the topics and items of interest embedded within the textual data, and data analysis therefore progressed in tandem with data collection. Applied thematic analysis using annotations, memos, and open and axial coding were used to analyse both the interview transcriptions and additional documentation [16]. We explored how knowledge was exchanged between participants and the factors that either hindered or enabled the production and exchange of knowledge.

\section{Results}

To interpret the findings, and to ensure participant anonymity, core project participants were grouped according to their emerging roles in the project (Table 2).

\section{Perceived success factors}

Just over five years since its inception, the collaborative project has resulted in a range of outcomes linked to changes in knowledge, awareness, policy, practice and response actions. Perceptions on what elements of the project were 'successful' varied. For some, success was perceived to be in relation to the formation of new communities of practice and research networks. For others, success was linked to developing and linking new qualitative and quantitative models for understanding complex problems. Specifically, the role of ecosystem services in disaster management was made clear not only in scientific publications (e.g. $\left[13^{\bullet \bullet}\right]$ ), but also in stakeholder publications [17]. This knowledge was helpful in eliciting new perspectives and actions in the management of ecosystems and disasters (e.g. $\left[9^{\bullet \bullet}\right]$ ) across a wide group of stakeholders. These actions resulted in a suite of ecosystem-based response strategies initiated in Eden, including private and public investments, restoring ecosystem services, institutional changes to promote more pro-active disaster risk reduction and the establishment of multiple social-learning networks $\left[9^{\circ \bullet}\right]$.

However, most participants agreed that the processes of collaboratively designing the project, producing the knowledge, and developing and implementing the response strategies were its main successes, as highlighted by a knowledge broker: 'A large part of the success in Eden is that it spoke to what can be done over what can't be done and the power of the individual and organisations shared response to a problem'.

Participants did, however, mention some shortcomings of the project, inter alia the absence of a baseline assessment

\begin{tabular}{|c|c|}
\hline \multicolumn{2}{|c|}{ Broad topics for discussion in the interview guide } \\
\hline Broad topic & Main question categories \\
\hline Role in the project & $\begin{array}{l}\text { The way in which they became involved } \\
\text { The ways in which their different roles emerged } \\
\text { Other individuals with whom they closely collaborated }\end{array}$ \\
\hline Whether the project has been a 'success' & $\begin{array}{l}\text { Their definition of indicators of success } \\
\text { Their views on what important outcomes of the research should be } \\
\text { Satisfaction with the outcomes }\end{array}$ \\
\hline How knowledge was exchanged & $\begin{array}{l}\text { Role players with whom information was shared } \\
\text { Means of sharing information } \\
\text { Perceived barriers, if any, to knowledge exchange }\end{array}$ \\
\hline Learning, if any, that had occurred & $\begin{array}{l}\text { Whether they learnt anything new in terms of knowledge, skills or networks } \\
\text { Their opinion on whether others had learnt anything new in terms of knowledge, skills or networks }\end{array}$ \\
\hline
\end{tabular}




\begin{tabular}{|c|c|c|}
\hline \multicolumn{3}{|c|}{ Emerging roles of participants in the study } \\
\hline Role in the project & Description & Number \\
\hline Scientist & $\begin{array}{l}\text { Specialists in coastal engineering, climatology, marine ecology, hydrology, fire } \\
\text { ecology, biodiversity, climate change, ecosystem services and criminology }\end{array}$ & 7 \\
\hline Knowledge broker ${ }^{1}$ & $\begin{array}{l}\text { The three initiators of the research who were affiliated with an NGO, a research } \\
\text { institute and an insurer, as well as two additional scientists who joined the project } \\
\text { as roles emerged }\end{array}$ & 5 \\
\hline Private sector representative & $\begin{array}{l}\text { A risk underwriter, and individuals from the sustainability and stakeholder- } \\
\text { relations section of the insurance company }\end{array}$ & 3 \\
\hline Implementing agent & $\begin{array}{l}\text { Individuals from local and provincial government, specifically from departments } \\
\text { related to climate change adaptation, environmental management and disaster } \\
\text { risk reduction, and an individual from an NGO }\end{array}$ & 4 \\
\hline
\end{tabular}

that would have enabled more detailed analysis of the impact of the project or change in perceptions, as well as issues related to limited time, resources and institutional capacity to implement all the desired response strategies.

Despite different views on some of the details, participants unanimously agreed that the project had achieved most of its intended outcomes.

\section{Barriers to knowledge production and exchange}

Particular challenges emerged at the beginning of the project that had the potential to restrict processes of knowledge exchange, were they not addressed.

\section{Preconceived assumptions}

Preconceived assumptions concerning the motivations of other participants and institutions for embarking on the project emerged as a challenge to knowledge exchange. Initially there were many perceptions among participants about how others hoped to benefit from the project. Assumptions mostly centred on others' 'self-serving interests', either of advancing research careers and publishing papers (in the case of the scientists) or recouping costs and responding to corporate social responsibility (in the case of the private sector). There was also an initial assumption that the scientists and NGO were 'greenies' with an antidevelopment agenda.

\section{Embedded terminologies}

Different terminologies used by the various participants, which were entrenched in their respective disciplines or organisations, were regarded as a potential impediment to the project's progression. 'We all need almost like a Rosetta stone where we can come together', stated one of the knowledge brokers, whose view was supported by a scientist stating, 'We were totally talking past each other in the beginning'. Scientific terms such as 'ecological buffer', 'risk assessment', 'boundary' and 'hydrological regime' were cited by participants as problematic. The operational language of business was also not well understood by the scientists, resulting in presentation of findings that did not necessarily reconcile with the organisational systems and language of business.

\section{Entrenched thinking}

Discipline-embedded thinking and an initial resistance to new practices (e.g. the use of a particular assessment framework) emerged as an important barrier to knowledge exchange. At the onset it became apparent that participants' mental models differed regarding certain concepts, for example, 'ecosystem services', 'assessment' and, in particular, 'risk': some scientists had a more complex, systems view of risk involving an acceptance of uncertainty, while the private sector was seen to understand risk as something one could delimit and manage using static models, without much uncertainty.

Numerous participants stated that the entrenched way in which scientists exchange and produce knowledge needed to be addressed. Specifically, there was a need for scientists to consider more flexible and adaptive ways to apply their skills to address the issues at hand. This was raised not only by the private sector, but also by scientists performing the knowledge-brokering roles who found that some scientists were initially resistant to using new methodological approaches. Specialist scientists were often perceived by other participants as being 'blinkered'; indeed, there was very little initial interaction amongst the specialist scientists, who were perceived to have little interest in each other's findings and chose to remain within their disciplinary siloes. However, when some of the specialist scientists were asked about issues related to knowledge exchange, there was no mention of any of these difficulties. As a consequence some of the scientists were content to remain within their specialist fields, thus fulfilling only a narrow role in the project, as 
the results they produced needed to be translated by other participants in terms of how they contributed to the overall findings of the project.

\section{Factors facilitating knowledge exchange}

Contrary to the barriers, which emerged primarily within the initial months of engagement, several positive factors emerged throughout the research process that appeared to support knowledge exchange and integration.

\section{Co-creating the project}

An important factor facilitating knowledge exchange was the involvement of all participants in the design and implementation of the project and subsequent recommendation and response strategies. Although time consuming, this resulted in the project being perceived as being co-created by those involved, which was an intended outcome of the project. However, the intensity and desired level of engagement and participation among participants emerged as the project progressed. We identified four broad 'formal' types of engagement during the 3 year Eden project: partnership meetings, technical meetings, participant meetings and informal meetings. Most engagement sessions were planned and were largely problem or product driven, designed for knowledge exchange around an issue, for example, field trips to gain a sense of context, or writing meetings to communicate the findings of the project. Further, different participants were able to lead different work streams based on their expertise in, or knowledge of, a particular context or component which assisted with balancing power asymmetries and further facilitated a sense of co-creation and trust.

Partnership meetings were strategic meetings held primarily between the knowledge brokers and scientists, where higher-level issues (e.g. strategic direction of the project or key outcomes) were discussed. Technical meetings include specialist scientist involved in modelling natural hazards (wildfire, floods, storm waves or drought) or assessing social-economic contexts. Thereafter, knowledge brokers integrated the specialist reports, presented the integrated research at the partnership meetings, and then reported back to the scientists.

Participant meetings included all participants, and served to discuss findings, hypotheses and concerns. These engagements focused on knowledge integration, occurred once the technical research component of the project had been completed, and involved engaging with potential implementers of the response options outlined by the research. Implementers included decision makers in local and provincial government, and other interested and affected individuals and institutions (e.g. poverty alleviation programmes). Engagement during participant meetings took the form of meetings and presentations at, for example, stakeholder fora and at a side event at the 17th
Conference of the Parties to the United Nations Framework Convention on Climate Change.

Finally, 'informal' meetings were co-designed to ground the research in practice. These informal meetings included field trips - during which scientists and technical experts from local government and the private sector drove around the region visiting specific sites of interest - or other types of informal meetings at in the offices of participants.

Across these meeting types (of which there were more than 30), knowledge was produced and exchanged using diverse methods, including face-to-face meetings, workshops, field trips, online video meetings, telephone calls or reports attached to email correspondence. In addition to the formal, planned meetings that were recorded, informal 'drop-in' meetings where specific issues (e.g. model components, data sharing) were discussed were held, mainly in the offices of the scientists. There was little to no participant turnover, although there was variation in terms of participants' respective levels of engagement based on the planned work streams. The knowledge brokers also spent substantial time together, especially near the end of the project, when they collaborated to interpret the results and design strategic project messages and response strategies for various stakeholders, both involved in, and external to the project, for example, the biodiversity sector and implementing agents in the public and private sector.

Many participants had not engaged in this type of multipartner project before, but they indicated that they are using insights derived from this mode of engagement in their subsequent work, especially to develop new research partnerships. The value for business of engaging with research institutions was articulated as follows by an individual from the private sector: "when you have academic evidence it is so much easier to position yourself. . .we found that we could bring substance to particular issues'.

Joint activities which facilitated co-learning over an extended time were regarded as crucial to knowledge exchange. According to a knowledge broker, 'the success of Eden is that we spent enough time to get to the final point; the social scientists, natural scientists, business people took enough time getting to know each other being together, working together, struggling together to get to something - but it took a lot of time'. There was therefore a general sense that the project results and insights were co-produced through collaborative problem solving.

\section{Knowledge brokers, mavericks and champions}

A frequently cited reason for the perceived success of the project was the presence of individuals who served as 'vital facilitators', 'integrators', 'champions', 'energisers' and 'agents of change': the knowledge brokers. We found that 
knowledge brokers had flexible roles depending on the project phase. For example, some were more active in integrating the individual results (e.g. results of a floodrisk model and coastal-risk models) into a coherent narrative, while others worked at a more strategic level to interpret findings for decision making at local to international levels for both the public and private sector. On the whole, knowledge brokers were not selected to be part of the project, as they were the main instigators of the research. However, the importance of their role emerged as the project progressed and they all recognized the value of co-designing the research and as such, ensured that the research was implemented in a participatory and collaborative way.

Knowledge brokers facilitated dialogue amongst participants, and provided an enabling environment for knowledge exchange: the broader problem was translated into researchable components, and then synthesised later to tell a coherent and compelling story. The coherence was viewed as an important part of joint problem solving, in that all the research activities needed to be bound or directed by the broader research question. Knowledge brokers further actively - and, it was said, 'painstaking$l y$ ' - facilitated constant dialogue, thereby transforming historically isolated silos (e.g. the private sector and scientists) and their associated 'monologues' of entrenched disciplinary/sectoral language into a two-way process of communication through which assumptions and agendas could be addressed, and assisted greatly in lifting some of the initial barriers of language and misperceptions.

Knowledge brokers were regarded as 'big-picture thinkers', 'innovative experts in their fields', and, importantly, 'passionate individuals' who were committed to eliciting change. In describing the knowledge brokers, the label 'champion' was used by a variety of participants. These 'champions' were considered crucial for ensuring institutional buy-in, as well as garnering support for the research beyond the institutions involved in the project, by presenting the findings at multiple fora, both locally and internationally. Another term for the champions, suggested by an implementing agent, was 'mavericks', as the knowledge brokers were perceived to be traversing new or unconventional territory by facilitating engagement among institutions that had not collaborated before, and had seemingly irreconcilable aims (e.g. those of business and conservation). Despite the vital role played by champions in driving the research and garnering support for it, one of the knowledge brokers cautioned that, while it is important to involve champions, they themselves are somewhat more sceptical about their role, and question the motivation for championing a cause, because sometimes 'one wants to be the champion and so can hold one's cards very closely to one's chest', thereby excluding other role players in order to gain a competitive advantage professionally.
Knowledge brokers further articulated that the project was deliberately exploratory and 'document-free', because the novelty of the work, and therefore no one had previous experience to draw on. Maintaining a constant dialogue assisted with finding new ways of engaging and sharing knowledge amongst participants, and allowed for joint ownership, and integration, of the research, as indicated by a knowledge broker for whom the project 'wasn't about control; we allowed something to emerge - it was a very creative process and we co-created something that had multiple meanings so [X] can go on and do something with it, and I can go and do something with it'. Facilitating dialogue was especially important for the scientists to gain a better understanding of how business operates, in order to find a common language with which to communicate.

\section{Trust-building}

Participants' mutual trust in each other's abilities and the research process emerged as an important enabling factor of the knowledge-exchange process. Trust was referred to explicitly either in relation to the specific technical aspects of research being conducted, or more generally in relation to the research process as a whole. Competence-based trust also emerged, although more implicitly, as evinced by the use of terms synonymous with trust, such as confidence or belief in each other's capabilities. However, it is interesting to note than one of the scientists referred to the 'blind faith' that other participants had in the science component of the work, in particular business which 'has a scary trust in scientists' and that therefore, as scientists, they 'have a big responsibility to not abuse the trust and to be upfront about the limitations and assumptions of the research'. References were also made to participants creating a 'safe space' where they trusted one another sufficiently to be honest and truthful, even though they did not always agree with each other.

\section{Systems thinking grounded in practice}

The deliberate use of systems thinking in the research process compelled participants to conceptualise extreme events and disaster risk in a more holistic and systemic way, as articulated by a knowledge broker: 'everybody was so focused on the science and so focused on specific slices of the problem, and this was the first systemic look at it - how you can actually do it in an area - and it was quite real, because it was linked to an area and was not just theoretical'. Shifting disaster management from the conventional social or infrastructure focus to a broader appreciation of the role of ecosystems and their services was perceived to be essential. Illustrating and providing quantitative evidence of the practical connections between social and ecological phenomena, and how they impact business in an interrelated and often reinforcing way, assisted with communicating the important role that healthy ecosystems can play in mitigating disasters. Using a systems view was also perceived to be crucial in co-designing systemic response strategies across sectors that targeted multiple benefits 
and brought diverse stakeholders together across sectors. Importantly, using a systems lens enabled links to be made between local and national policies and decisionmaking processes, especially in relation to disaster management.

Further, the project was perceived as 'live', as opposed to merely a science experiment, as articulated by a knowledge broker: 'it's live people running around thinking about stuff and then making decisions in the real world, and it's messy'.

For participants, the project provided new ways to think about or understand the challenges they faced in their work or 'practice', for example, challenges associated with integrating different disciplines, choosing between ecosystem management options, using science to inform or alter current risk management practices, or communicating science in user-useful and user-driven ways.

\section{Discussion}

\section{Co-designing the project and facilitating dialogue}

Analysing the experiences and learning of participants engaged in an innovative, transdisciplinary project that was grounded in practice, provided fertile ground to explore current thinking about knowledge exchange. The early phases of the Eden project were hampered by a lack of knowledge about the process of co-designing research and how to address issues such as preconceived assumptions, entrenched disciplinary thinking, divergent terminology, mental models and value systems and a general lack of trust. Our results indicate that the deliberate process of establishing or co-designing the project together was vital in overcoming these errors in the early phases which slowed progress. The brokering of knowledge between different knowledge communities of stakeholders was found to be crucial in overcoming these issues, as well as for promoting an approach to systems thinking that is grounded in practice.

Although the central role of communication in improving knowledge exchange within the science-practice interface has been raised by others [18-20], our study provides examples of how diverse groups of participants, within a knowledge-exchange process, experience and overcome communication and trust-building issues in practice, to arrive at a shared understanding of an issue, especially one pertaining to ecosystem management $\left[8^{\circ \bullet}\right]$. Here we intentionally use the term science-practice interface, in preference to science-policy interface, to signal a move beyond the drafting of policies, to the interface between scientists and those individuals or institutions engaged in on-the-ground activities or actions that alter social-ecological system dynamics, for example, restoration activities or alteration of landuse planning policies.
Some participants did mention perceived shortcomings of the project, linked to common issues related to limited time, resources and implementation capacity $\left[7^{\circ}\right]$ and the lack of a pre-designed monitoring and evaluation strategy, which hampered evaluation efforts. In this regard, implementing a theory of change methodology at the beginning of the project would have been useful [21].

Facilitating dialogue is important in knowledge-exchange processes [20], and maintaining continuous dialogue throughout a research process improves the likelihood of its uptake [22]. In the Eden project, dialogue did not merely involve individuals talking to each other; rather, it was an active process of knowledge sharing, exchange and co-production. This process was facilitated by knowledge brokers through multiple types of engagement, enabling the co-production of knowledge for enhancing understanding of disaster risk, and co-designing response strategies $\left[9^{\bullet \bullet}, 13^{\bullet \bullet}\right.$. This required active participation to ensure the incorporation of a variety of different knowledge types, arguments and preferences in the findings. By the project end there was a sense of a shared understanding of the role of ecosystems for mitigating disaster risk, and a joint commitment to mobilising future action [ $\left.9^{\bullet \bullet}\right]$. Importantly, the project resulted in the development of new networks and research collaborations which can assist with post-project sustainability $\left[9^{\bullet \bullet}\right]$.

Although managing disasters emerged as a common objective with which to communicate across boundaries, definitions of specific concepts varied among participants and sufficient time was required to negotiate mutual understanding to design appropriate response strategies [23]. Individuals from the public and private sector, scientists and NGO workers belong to different epistemological communities [24]. Thus it is vital to acknowledge, early on in the research process, the resultant varying perceptions, assumptions and world views of participants in relation to the research problem, especially in the context of contested resources as one expects ecosystem services to be $\left[25^{\circ}\right]$. Facilitating dialogue is important in this regard, especially when conducted in a way that does not alienate dissenting voices and careful attention should be paid to the significant role that power can play in shaping legitimate participatory processes [26].

Although there were many different motives for participating in the Eden project - e.g. insurance interest in reducing the risk of insured assets in the landscape, ecologist interest in producing evidence of the role healthy ecosystems play in mitigating risk, implementing-agency interest in mobilising action - all participants shared the goal of reducing disaster risk in the region. Thus, there was multi-stakeholder demand for the research. Similar to [27], it was found that, by acknowledging the practical demand for the research, as well as focusing on joint problem 
development [28], knowledge-exchange activities were facilitated.

\section{Facilitating boundary work}

Managing the boundaries between disciplines and institutions, and between different types of knowledge (e.g. technical vs experiential) is vital for knowledge exchange $\left[8^{\bullet \bullet}, 29\right]$ and a breakdown in communication across the boundaries can hinder effective knowledge exchange [29]. Both the deliberate and emergent role that the knowledge brokers played was extremely important in facilitating trust-building and knowledge co-production across and within disciplinary, institutional and knowledge boundaries.

Scientists were perceived to be the most resistant to crossing knowledge boundaries and embracing new conceptual frameworks. Instead they preferred to use existing, disciplinary-based conceptual frameworks, as reported elsewhere [29-32]. However, the promotion of systems thinking assisted scientists to recognize how their individual research components contributed to understanding the interrelationship between various drivers of risk (e.g. ecosystem degradation and unplanned urban development) $\left[9^{\bullet \bullet}, 33\right]$. Systems thinking also aided in changing insurers' perceptions of the role the insurance industry can play in mobilising change, both in terms of the way it underwrites risk, and its support of risk-reduction programmes in other sectors, for example, capacitating municipalities in partnership with local government initiatives $\left[9^{\bullet \bullet}\right]$. These altered perceptions and improved common understanding assisted with the co-design of a suite of response strategies that addressed their respective mandates and interests and stimulated collective action towards addressing disaster risk reduction.

\section{Developing communities of practice for ecosystems- based disaster management}

Wenger [34] asserts that communities of practice are the most basic building blocks of a social learning system and thus the concept of communities of practice holds particular promise in understanding, and designing for, learning in multi-disciplinary processes $\left[35^{\circ}\right]$. Three elements are essential to constitute a community of practice $\left[35^{\circ}\right]$ which in Eden related to: a shared domain of interest (i.e. reducing risk in Eden); a community engaged in joint activities and learning (e.g. sharing information or developing flood models); and a practicing community, that is, be practitioners that develop shared processes for problem-solving [36]. Several communities of practice, with different levels of participation, emerged during the Eden project. The core group, constituted primarily of the knowledge brokers, met regularly, spending time together away, and engaging with various other stakeholders at multiple governance levels to garner interest and support and, importantly, link the research to potential action. Other communities of practice comprised scientists researching specific technical aspects of the project (e.g. conducting organisational analysis or constructing fire models), connecting with each other through boundary objects (e.g. documents, maps or models) around which communities of practice could organise their research linkages $\left[37^{\bullet}, 38\right]$. Boundary objects refer to approaches or methods to facilitate action in the context of complex systems, where information of the system is incomplete [38].

Ecosystem service science has produced very useful boundary objects (e.g. ecosystem service maps and models) that are of value for decision makers. However, as these are often not co-developed with their end users, they cannot act as connectors between different communities of practice (e.g. ecosystem scientists, land-use planners and decision makers), and as such cannot effectively contribute to closing science-practice gaps [39]. Co-producing ecosystem service products using a communities-of-practice model of engagement can turn these into valuable boundary objects which encapsulate the application context, and are therefore most likely to result in 'socially robust' knowledge which is crucial for applied research [40]. However, while boundary objects may initially facilitate dialogue among stakeholders, they can represent different mental models and have contrasting meanings to different groups at a deeper level [41], and highlight the importance of paying careful attention to both the process and the products of knowledge coproduction.

Communities of practice need effective leadership; here knowledge brokers in the Eden project played a significant role. Boundaries between the communities of practice became important 'spaces' for learning opportunities [34]. Communities of practice are important because they allow for the transfer of both tacit and experiential knowledge, which are both crucial for implementing ecosystem management $\left[10^{\bullet \bullet}, 28,40\right]$.

\section{Conclusion}

Key to integrating ecosystem knowledge into the decisions that drive development is to identify important factors that facilitate or hamper knowledge-production and exchange processes that are geared for action. Our study provided a systematic approach to exploring factors that enabled and obstructed knowledge exchange during an interdisciplinary and multi-stakeholder engagement process that was designed in order to better inform the management of disasters in Eden. By following a qualitative approach, which acknowledges the context-specific nature of the perceptions of the participants, a deeper understanding of the complex social conditions that facilitated knowledge production was developed [42]. Such an understanding is crucial, as the final uptake of findings 
in policy and practice is often more dependent on the context of scientists and users, and on relationships and mutual understanding, than on the attributes of the research results.

\section{Acknowledgements}

The authors are appreciative to all the stakeholders involved in this research for their time, openness and willingness to share their knowledge and experience. The National Research Foundation (NRF), Council for Scientific and Industrial Research (CSIR), Stellenbosch University (SU) and the Transdisciplinary, Sustainability, Analysis, Modelling and Assessment (TSAMA) Hub provided financial and other support. We further acknowledge the financial support of the United Nations Environment Programme and the Global Environment Facility through Project for Ecosystem Services (ProEcoServ), and the Southern African Programme on Ecosystem Change and Society (SAPECS) for providing a collaborative and supportive research environment. We also thank our reviewers for their time, comments and recommendations.

\section{References and recommended reading}

Papers of particular interest, published within the period of review, have been highlighted as:

- of special interest

•• of outstanding interest

1. Munang R, Thiaw I, Alverson K, Mumba M, Liu J, Rivington M:

- Climate change and ecosystem-based adaptation: a new pragmatic approach to buffering climate change impacts. Curr Opin Environ Sustain 2013, 5:67-71.

An analysis of the interconnections between climate change, ecosystems and disaster risk and the importance and opportunities of proactive ecosystem management.

2. Jones HP, Hole DG, Zavaleta ES: Harnessing nature to help people adapt to climate change. Nat Clim Change 2012, 2:504 509.

3. Buyck C, Dudley N, Furuta N, Pedrot C, Renaud FG, SudmeierRieux K: Protected Areas As Tools for Disaster Risk Reduction: A Handbook for Practitioners. Japan Ministry of the Environment, Japan and IUCN, Gland; 2015.

4. Renaud FG, Sudmeier-Rieux K, Estrella M: The Role of Ecosystems in Disaster Risk Reduction. United Nations University Press; 2013.

5. Simonit S, Perrings C: Sustainability and the value of the 'regulating'services: wetlands and water quality in Lake Victoria. Ecol Econ 2011, 70:1189-1199.

6. Arkema KK, Guannel G, Verutes G, Wood SA, Guerry A Ruckelshaus M, Kareiva P, Lacayo M, Silver JM: Coastal habitats shield people and property from sea-level rise and storms. Nat Clim Chang 2013, 3:913-918.

7. Sitas N, Prozesky HE, Esler KJ, Reyers B: Opportunities and

- challenges for mainstreaming ecosystem services in development planning: perspectives from a landscape level. Landsc Ecol 2014, 29:1315-1331.

Highlights the opportunities and challenges for integrating ecosystem service information into development planning at a local level with a focus on multi-sectoral planning and disaster risk reduction.

8. Fazey I, Evely AC, Reed MS, Stringer LC, Kruijsen J, White PC,

-• Newsham A, Jin L, Cortazzi M, Phillipson J: Knowledge exchange: a review and research agenda for environmental management. Environ Conserv 2013, 40:19-36.

An interesting review on knowledge exchange which identifies a research agenda for further theory and practice on enhancing knowledge exchange for future sustainability.

9. Reyers B, Nel JL, O'Farrell PJ, Sitas N, Nel DC: Navigating

- complexity through knowledge coproduction: mainstreaming ecosystem services into disaster risk reduction. Proc Natl Acad Sci U S A 2015, 112:7362-7368.

Presents a novel approach for coproducing knowledge and action for enhanced ecosystem management using a social-ecological systems lens.
10. Tengö M, Brondizio ES, Elmqvist $T$, Malmer $P$, Spierenburg $M$ :

-• Connecting diverse knowledge systems for enhanced ecosystem governance: the multiple evidence base approach. Ambio 2014, 43:579-591.

Outlines an approach for integrating diverse knowledge types for enhanced understanding and governance of biodiversity and ecosystems for human well-being especially in relation to future assessments and efforts (e.g. IPBES).

11. Doswald N, Munroe R, Roe D, Giuliani A, Castelli I, Stephens J, Möller I, Spencer T, Vira B, Reid H: Effectiveness of ecosystembased approaches for adaptation: review of the evidencebase. Clim Dev 2014, 6:185-201

12. Arkema KK, Verutes GM, Wood SA, Clarke-Samuels C, Rosado S, - Canto M, Rosenthal A, Ruckelshaus M, Guannel G, Toft J: Embedding ecosystem services in coastal planning leads to better outcomes for people and nature. Proc Natl Acad Sci U S A 2015, 112:7390-7395.

Highlights the benefits of including ecosystem services information into coastal planning processes that can deliver enhanced social-ecological outcomes.

13. Nel JL, Le Maitre DC, Nel DC, Reyers B, Archibald S, van

-• Wilgen BW, Forsyth GG, Theron AK, O'Farrell PJ, Kahinda J-MM: Natural hazards in a changing world: a case for ecosystembased management. PloS One 2014, 9:e95942.

Presents an interesting case linking land-use activities to an increase in natural hazards and highlights the importance of well-managed and intact landscapes for reducing the impacts of extreme events.

14. Glaser BG, Strauss AL, Strutzel E: The discovery of grounded theory; strategies for $\mathbf{4 7 3}$ qualitative research. Nursing Res 1968, 17:364.

15. Creswell JW: Research Design Qualitative Quantitative and Mixed Methods Approaches. 4th edn. SAGE Publications, Inc.; 2014.

16. Guest G, MacQueen KM, Namey EE: Applied Thematic Analysis. Sage Publications, Inc.; 2011.

17. UNEP FI: Insurance in a Changing Risk Landscape: Local Lessons from the Southern Cape of South Africa. United Nations Environment Programme Finance Initiative; 2012.

18. Vogel C, Moser SC, Kasperson RE, Dabelko GD: Linking vulnerability, adaptation, and resilience science to practice: pathways, players, and partnerships. Glob Environ Chang 2007, 17:349-364.

19. Margoluis R, Stem C, Salafsky N, Brown M: Using conceptual models as a planning and evaluation tool in conservation. Eval Prog Plan 2009, 32:138-147.

20. Cornell S, Berkhout F, Tuinstra W, Tàbara JD, Jäger J, Chabay I, de Wit B, Langlais R, Mills D, Moll P: Opening up knowledge systems for better responses to global environmental change. Environ Sci Policy 2013, 28:60-70.

21. Prager $K$, Reed M, Scott $A$ : Encouraging collaboration for the provision of ecosystem services at a landscape scale rethinking agri-environmental payments. Land Use Policy 2012, 29:244-249

22. Godfrey L, Funke N, Mbizvo C: Bridging the science-policy interface: a new era for South African research and the role of knowledge brokering. S Afr J Sci 2010, 106:44-51.

23. Vignola R, McDaniels TL, Scholz RW: Governance structures for ecosystem-based adaptation: using policy-network analysis to identify key organizations for bridging information across scales and policy areas. Environ Sci Policy 2013, 31:71-84.

24. Dunlop CA: The possible experts: how epistemic communities negotiate barriers to knowledge use in ecosystems services policy. Environ Plan C: Government Policy 2014, 32:208-228.

25. Schröter M, van der Zanden EH, van Oudenhoven APE,

- Remme RP, Serna-Chavez HM, de Groot RS, Opdam P:

Ecosystem services as a contested concept: a synthesis of critique and counter-arguments. Conserv Lett 2014, 7:514-523. A synthesis of critiques and respective counter-arguments of the concept of ecosystem services.

26. Stringer LC, Dougill AJ, Fraser E, Hubacek K, Prell C, Reed MS: Unpacking 504 "participation" in the adaptive management of 
social-ecological systems: a critical 505 review. Ecol Soc 2006, 11:39.

27. Honey-Rosés J, Pendleton LH: A demand driven research agenda for ecosystem services. Eco Serv 2013, 5:160-162.

28. Jahn T, Bergmann M, Keil F: Transdisciplinarity between mainstreaming and marginalization. Ecol Econ 2012, 79:1-10.

29. Cash DW, Clark WC, Alcock F, Dickson NM, Eckley N, Guston DH, Jäger J, Mitchell RB: Knowledge systems for sustainable development. Proc Natl Acad Sci U S A 2003, 100:8086-8091.

30. Ziervogel G, Taylor A: Feeling stressed: integrating climate adaptation with other priorities in South Africa. Environ Sci Pol Sust Dev 2008, 50:32-41.

31. Bruce A, Lyall C, Tait J, Williams R: Interdisciplinary integration in Europe: the case of the Fifth Framework programme. Futures 2004, 36:457-470.

32. Hadorn GH, Hoffmann-Riem H, Biber-Klemm S, GrossenbacherMansuy W, Joye D, Pohl C, Wiesmann U, Zemp E: Handbook of Transdisciplinary Research. Springer; 2008.

33. Norström A, Dannenberg VA, McCarney G, Milkoreit M, Diekert F, Engström G, Fishman R, Gars J, Kyriakopoolou E, Manoussi V et al.: Three necessary conditions for establishing effective Sustainable Development Goals in the Anthropocene. Ecol Soc 2014, 19:8

34. Wenger E: Communities of practice and social learning systems. Organization 2000, 7:225-246.
35. Cundill G, Roux DJ, Parker JN: Nurturing communities of practice for transdisciplinary research. Ecol Soc 2015:20. Introduces the concept of transdisciplinary communities of practice for global sustainability science and highlights key lessons for people engaging in this research space.

36. Wenger E, McDermott RA, Snyder W: Cultivating Communities of Practice: A Guide to Managing Knowledge. Harvard Business Press; 2002

37. Nel JL, Roux DJ, Driver A, Hill L, Maherry A, Snaddon K,

- Petersen C, Smith-Adao LB, Van Deventer H, Reyers B: Knowledge co-production and boundary work to promote implementation of conservation plans. Conserv Biol Early View 2015 http://dx.doi.org/10.1111/cobi.12560.

Highlights the importance of knowledge co-production processes in the development of boundary objects that can increase the impact of conservation planning processes and enhanced utility of resulting products.

38. Mollinga PP: Boundary work and complexity of natural resource management. Crop Sci 2010, 50:1-9.

39. Sitas N, Prozesky H, Esler KJ, Reyers B: Exploring the gap between ecosystem service research and management in development planning. Sustainability 2014, 6:3802-3824.

40. Nowotny $\mathrm{H}$ : Democratising expertise and socially robust knowledge. Sci Public Policy 2003, 30:151-156.

41. Star SL: This is not a boundary object: reflections on the origin of a concept. Sci Technol Hum Val 2010, 35:601-617.

42. Cundill GN, Fabricius C, Marti N: Foghorns to the future: using knowledge and transdisciplinarity to navigate complex systems. Ecol Soc 2005, 10:8 